\title{
O sistema da língua, o diálogo e o discurso
}

Ana Zandwais ${ }^{1}$

\begin{abstract}
The objective of this article developed at Post-Graduate studies at Federal University of Rio Grande do Sul State is to reflect on the conception of discourse, as a complex object, constituted of opacity and hybridity. For investigating this conception, we will analyse some important notions introduced in the Soviet context by Valentin N. Voloshinov, Mikhail M. Bakhtin and Lev Jakubinskij, during the first decades of the twentieth century, that not only contributed to the construction of the conception of discourse but also influenced the basis of important studies developed about the notions of dialogue, heterogeneity and ideology, in European context, by famous french semanticists, linguists and philosophers as Oswald Ducrot, Jacqueline Authier-Revuz and Michel Pêcheux.
\end{abstract}

Keywords: Discourse; subject; sense; ideology.

Resumo: O objetivo deste artigo consiste em refletir sobre a concepção de discurso, como um objeto complexo, constituído por opacidade e hibridez. A fim de investigar esta concepção, analisaremos algumas noções importantes introduzidas no contexto soviético por Valentin Voloshinov, Mikhail. M. Bakhtin e Lev Jakubinskij, durante as primeiras décadas do sec. xx, as quais não somente contribuíram para a construção de uma concepção de discurso mas também influenciaram as bases de estudos importantes sobre as noções de polifonia, heterogeneidade e ideologia, desenvolvidas por semanticistas, lingüistas e filósofos franceses como Oswald Ducrot, Jacqueline Authier-Revuz e Michel Pêcheux.

Palavras-Chave: Discurso; língua; sentido; ideologia.

Introdução

Investigar o discurso, como uma materialidade, buscando analisar os modos como este trabalha, requer reflexões para além do sistema da língua. O propósito implica pensar sobre as formas através das quais os sentidos trabalham, considerando o fato de que estes não podem ser totalmente traduzidos por meio de estruturas sintáticas.

Esta tarefa, por outro lado, demanda pressupor que na própria concepção de discurso há uma condição de heterogeneidade que necessita ser descrita através do funcionamento de diferentes relações transversas:

a) uma relação entre história e acontecimento;

b) uma relação entre língua, ideologia e sentido

c) relações entre enunciado e temporalidade.

1 Docente do Programa de Pós-Graduação em Letras da UFRGS. Membro do Comitê Editorial da Revista 'Conexão Letras'. Coordenadora do Projeto 'História das Idéias: diálogos entre linguagem, cultura e história'. 
Segundo nosso ponto de vista, um dos obstáculos mais expressivos para que se compreenda como o discurso funciona pode ser explicado pelo fato de que mesmo sendo constituído por uma materialidade lingüística, ele não pode ser reduzido a esta materialidade e, por esta razão, escapa ao "olhar” do lingüista como um objeto empírico de natureza híbrida.

\section{O Discurso Como Objeto Empírico}

Podemos afirmar, ao iniciarmos esta reflexão, que a constituição do discurso pode ser compreendida, ao mesmo tempo, pela ordem simbólica - a linguagem - e por valores ideológicos que as palavras assumem, enquanto reflexos de contradições entre as superestruturas e a infraestrutura (forças sociais).

O discurso, deste modo, poderia ser descrito como um processo que precisa ser explicado, enquanto materialidade concreta, de acordo com os interesses das formações sociais e com as diferentes práticas que refletem tais interesses através do modo como são produzidas e inscritas em um objeto simbólico - a língua.

Por outro lado, quando caracterizamos o discurso por refletir práticas sociais e o modo como as estratificações sociais dividem os sujeitos no interior de uma língua, seguindo os princípios de raznorechie ${ }^{2}$ propostos por Lev Jakubinskij $(2012)^{3}$ e, sobretudo a noção de heteroglossia (raznoiaziche), abordada por Mikhail Bakhtin em 'O Discurso no Romance (1981), podemos afirmar que uma língua nacional é uma composição híbrida constituída, ao mesmo tempo pela unidade e pela estratificação de muitas línguas.

Segundo Lätheenmaki (2005) em "Estratificação Social da Língua no Discurso Sobre o Romance: o contexto soviético oculto," as noções de raznorechie e raznoiaziche exploram as relações entre língua e sociedade e nos fornecem a possibilidade de pensar não somente que uma língua é a conjunção de muitas línguas, mas que o discurso é também uma hibridação de diferentes discursos.

Voloshinov (2009) , no início do sec. xx, em seu estudo intitulado 'Chto Takoe Yazik' [ O Que é a Língua e a Linguagem], na tentativa de analisar fatos da língua para além da hegemonia do positivismo desse século, no 'Leste', e das influências das ideias cartesianas $^{5}$ no 'Oeste' investigou importantes propriedades da linguagem, considerando-a como 'um corpo material que reflete um corpo social'.

De acordo com sua ótica (2010:523) "há uma profunda diferença entre o caráter verbal material e qualquer outro material de ordem exclusivamente física". Ao trabalhar

2 Mika Lätheenmaki aborda as ideias de L. Jakubinskii em 'Estratificação Asocial da Linguagem No Discurso Sobre o Romance'. In: Mikhail Bakhtin: contribuições para a Filosofia da Linguagem e estudos discursivos.' ZANDWAIS, Ana (org.), Porto Alegre: Ed. Sagra-Luzzatto,, p. 41-58.O termo raznorechie pode ser traduzido como 'um discurso em outro discurso'.

3 Fazemos referência ao texto 'O Dialogicheskoi rechi'publicado em Moscou pela Nauka Edições e ao texto 'Lev Jakubinsky: une linguistique de la parole' publicado pela Lambert-Lucas Editions, 2012. Lev Petrovič Jakubinskij foi um dos fundadores do 'Instituto da Palavra Viva", que visava a privilegiar os estudos da oralidade a fim de desenvolver entre o povo soviético capacidades como desenvoltura, auto-confiança e domínio da expressão linguística, objetivando formar uma nova sociedade de letrados de caráter inclusivo.

4 Estamos trabalhando neste estudo com duas traduções: a edição bilíngue 'Qu'est ce que la langue et le langage'. Limoges: Ed. Lambert-Lucas, 2010, p.521-566 traduzida para Francês por Patrick Sériot e Inna-Tilkowsky Ageeva e com a tradução brasileira da publicação em Espanhol acrescida de notas 'Que é a Linguagem' produzida por João Wanderley Geraldi (São Carlos: Ed. Pedro \&João) com vistas a comparar as equivalências.

5 É importante enfatizar, de acordo com Sériot (2010:65) que Voloshinov recusa o modelo cartesiano de língua que propõe um status prévio do pensamento determinando o caráter da língua. Ele recusa também a visão idealista de que o mundo das ideias determina a realidade. 
com a linguagem, um autor trabalha simultaneamente com regras e com significados prédados, não obstante estes possam ser ressignificados de acordo com a vida em sociedade. A linguagem, de acordo com ele, "se reflete através de todos os seus elementos: econômicos, sociais e de acordo com a organização política de uma sociedade" (op.cit., p.539).

Considerando as questões expostas acima, poderíamos entender o discurso não somente como uma materialidade verbal composta das propriedades de coesão e coerência ${ }^{6}$. Poderíamos compreender nosso objeto como uma unidade mais complexa que precisa ser pensada sob condições sociais e históricas, as quais determinam o trabalho dos signos na linguagem. E este seria o princípio que permite elucidar o discurso como um objeto híbrido que não pode estar situado somente no terreno da Linguística.

Faz-se necessário enfatizar também que de acordo com Volochinov (1973:110) ${ }^{7}$ em 'Marxism and the philosophy of language' o estatuto dos enunciados no cenário dos estudos lingüísticos teria sido sempre descrito de modo incerto. De acordo com Volochinov ' na medida em que o enunciado na sua totalidade permanece como terra incognita para o lingüista (op.cit., p.110) parece ser difícil compreender o discurso como uma unidade de sentidos.

Quanto mais próximo o lingüista está das fronteiras entre os enunciados mais inseguras tornam-se suas posições, considerando-se que as estruturas morfológicas e sintáticas não são mais suficientes para explicar as formas concretas através das quais a linguagem funciona como um corpo material de um corpo social.

As condições que transformam as categorias lingüísticas em enunciados concretos, segundo Volochinov (1973) estão colocadas fora da língua, se esta for compreendida como sistema, desde o ponto de vista do objetivismo abstrato. ${ }^{8}$ Portanto, a fim de tratar de enunciados concretos como discurso é necessário, antes de tudo, superar a fragmentação entre língua e ideologia.

É preciso considerar, por outro lado, que não obstante a impossibilidade de delimitar as fronteiras entre questões lingüísticas e ideológicas, tais relações não são simétricas. Não se podem substituir umas pelas outras.

O discurso, compreendido sob esta perspectiva, portanto, não pode negar seu conteúdo formal, nem suas modalidades de orientação social que pressupõem diferentes formas dialógicas de interação, as quais representam as tendências de inscrição dos signos em universos históricos e sociais que são tanto heterogêneos como complexos.

Volochinov ainda nos mostra que a 'consciência linguística' dos falantes não pode subordinar-se a uma simples forma linguística porque compreender como a consciência funciona em enunciados concretos pressupõe um contexto ideológico capaz de apresentar as palavras como sendo flexíveis e mutáveis. Assim, de acordo com este enfoque, as palavras que compreendemos e suscitam reações em nós são aquelas que produzem ressonâncias ideológicas.

6 Reportamos nossos comentários às definições de texto encontradas em M.A.K. Halliday \& R. Hasan, 'Cohesion in English' (London: Longman, 1976, p.1) onde texto e discurso podem remeter a 'qualquer passagem falada ou escrita, de qualquer extensão, que constitua uma unidade.

7 Estamos trabalhando com a versão inglesa de 'Marxismo e Filosofia da Linguagem' (Harvard: Harvard University Press, 1973) traduzida da língua Russa por Ladislav Matejka e I. R. Titunik e também com a versão brasileira da língua Francesa traduzida por Iara Frateschi, Michel Lahud et al (São Paulo: Ed. Hucitec, 1986). Na versão brasileira a autoria aparece exatamente como na tradução francesa. A tradução para língua Portuguesa é de nossa responsabilidade.

8 É importante lembrar que Voloshinov em 'Marxism and the Philosophy of Language' (1973:71) enfatiza que a linguagem sob o ponto de vista do estruturalismo pode ser caracterizada como um produto já acabado de geração para geração. De acordo com sua perspectiva, ' ao reificar o sistema da língua a corrente do objetivismo abstrato' trata as palavras vivas como se fossem mortas. 
Mikhail Bakhtin in 'O discurso na Poesia e o Discurso no Romance' (1990) ${ }^{9}$ levanta uma questão que consideramos essencial para o tratamento do discurso como nosso objeto de estudo. Ele observa que fatos de discurso não podem ser reduzidos aos limites do discurso dialógico empírico como geralmente fazem os lingüistas para tratar o diálogo. É importante considerar que o percurso dialógico envolve não somente relações entre o discurso do outro no discurso de cada um, mas também orientações para múltiplas linguagens sociais dentro dos limites de um horizonte sócio-ideológico. E tais características dos discursos apresentam suas próprias fronteiras como não delimitadas; em outras palavras, as fronteiras não são marcadas nem transparentes.

Deste modo, considerando os aspectos acima, poderíamos identificar em 'O Discurso na Poesia e o Discurso no Romance' uma noção de discurso que o caracteriza por sua complexidade.

De acordo com esta perspectiva, é importante compreender o discurso e as condições nas quais os enunciados concretos são produzidos, através do modo substancial como as palavras do outro resistem no discurso de cada um.

As palavras do outro podem nos responder, perguntando, dando assentimento, argumentando, julgando ou mesmo negando os sentidos de nossas palavras. Este movimento que parece ser invisível, é, ao mesmo tempo, fundador do discurso e responsável pelo modo como ele opera.

Observando o objeto de nossa investigação por esta perspectiva, mas indo além tornase importante analisar os modos como os enunciados e os eixos temáticos são articulados para que se compreenda a orientação de um tema e o modo como a significação trabalha, estabelecendo uma cadeia complexa composta por posições ideológicas que fornecem identidade ao discurso como uma unidade temática ${ }^{10}$.

As palavras do outro nas nossas palavras compõem nosso objeto - o discurso - como sendo híbrido, mas esta mistura de palavras tem seu próprio percurso sob certas condições históricas e sob diferentes formas de interação concreta. E os modos como os sujeitos interagem na sociedade determinam os tipos de práticas que necessitamos observar.

De acordo com Voloshinov (1973), o centro que organiza nossa expressão não é somente interior, mas, sobretudo externo. Considerando esta perspectiva, podemos dizer que a significação não consiste do simples conteúdo dos signos verbais. O significado, desta forma, é potencial, pois depende ao mesmo tempo do sistema da língua e das referências externas (exotópicas), considerando de modo fundamental os valores atribuídos às palavras em acontecimentos históricos e espaços diferentes.

Se a língua, portanto, pode ser definida como um corpo material de um corpo social e o discurso, um objeto híbrido que reflete as contradições entre as superestruturas e a infraestrutura (forças sociais), precisamos pensar também que a organização social refletida sob a modalidade discursiva, é resultado do trabalho de sujeitos sociais e históricos.

É importante enfatizar que os valores dados às palavras no discurso implicam compreender que Volochinov (2010) trata a palavra (slovo) como parte do discurso (rech), sem considerar a divisão entre 'língua e fala', mas recolocando, antes de tudo, o sentido original da palavra logos.

Esta questão parece ser fundamental porque sua posição é bastante distinta das posições do estruturalismo europeu que separam a compreensão da língua como um sistema (social) de seu uso (individual).

9 Estamos trabalhando com a versão brasileira de 'O Discurso na Poesia e o discurso no romance'.

10 É importante observar que em uma nota de rodapé da versão inglesa de 'Marxismo e Filosofia da Linguagem' o termo é considerado provisório. Remete à significância do 'enunciado como um todo' . 
Precisamos considerar, ao mesmo tempo, que as palavras inscritas no discurso 'rech' não podem ser concebidas sem seus enunciados, sem as vozes que os compõem. E os enunciados referem-se sempre à voz do outro orientada dentro de determinadas condições históricas, dentro de um contexto ativo, articulando diferentes vozes que funcionam pela responsividade. Em outras palavras, é necessário inscrever as palavras do outro, seus valores em nosso mundo simbólico. Tais aspectos representam o modo como o discurso funciona como um todo, conferindo um lugar importante para o sujeito como um ser social. O caráter de nossa compreensão sobre a realidade, portanto, depende desse processo.

O sujeito, deste modo, não pode ser definido de forma pré-determinada, porque se constitui como sujeito em um processo onde a combinação de vozes com a voz do outro, com as significações do outro compõem seu universo simbólico, mas estas vozes e estes significados estão mesclados à sua voz e às suas significações no 'teatro da vida'. Eis a razão pela qual a dialogia não necessita de falantes empíricos.

Referindo-nos a 'Marxismo e Filosofia da Linguagem' (MFL) podemos dizer que há nesta obra bases fundamentais e precursoras da noção de subjetividade que serão empregadas nos estudos semânticos e marxistas da linguagem desenvolvidos mais tarde - resguardadas suas especificidades - por lingüistas como Oswald Ducrot ${ }^{11}$ em seu estudo intitulado 'Esboço de Uma Teoria Polifônica da Argumentação', Jacqueline Authier-Revuz, em seu estudo intitulado 'As não-coincidências do dizer' (1998) e pelo filósofo marxista Michel Pêcheux em seu estudo intitulado ' Análise Automática do Discurso ${ }^{12}$ (1990), onde ele trata de uma concepção não subjetiva de sujeito criticando as teorias idealistas.

Estas questões, deste modo, adquirem grande relevância histórica, sobretudo em 'Marxismo e Filosofia da Linguagem' (MFL), tendo em vista que uma leitura marxista sobre a subjetividade irá redefinir diferentes noções clássicas de sujeito por uma ruptura não somente com o objetivismo abstrato, mas também com uma visão idealista de sujeito que postula um sujeito auto- centrado.

Em 'Por Uma Filosófia do Ato Ético'13' (1997:8) Mikhail Bakhtin observa que somente podemos 'saber, interpretar e criar no mundo em que vivemos', considerando que produzimos juízos de valor através de experiências concretas. Mas tais experiências ocorrem em certas circunstâncias históricas e as vivenciamos situados em espaços sociais. Assim, somente como sujeitos socialmente situados podemos reconhecer-nos, reconhecer o outro e atribuir sentidos às coisas.

Segundo esta ótica, para Bakhtin, toda razão teórica perde sua consistência se não for sustentada por razões práticas porque é a partir das razões práticas que emergem as bases que dão sustentação ao sujeito no acontecimento singular de 'ser um sujeito' (id., p.20).

Considerando as condições acima, nossos enunciados não podem ser reduzidos a atos psicofísicos ou abstratos porque eles expressam o modo como as referências exotópicas

11 Referimo-nos ao estudo clássico de Oswald Ducrot intitulado 'O Dizer e o Dito' publicado em Português (Campinas, Ed. Da Unicamp, 1984) onde o autor apresenta sua teoria Polifônica da enunciação, embasado em uma interpretação dos estudos de Bakhtin sobre a polifonia. Neste estudo ele critica Ann Banfield por sua compreensão do estilo indireto livre em 'Ou l'epistemologie, le style et la grammaire rencontrent la theorie littéraire.' Langue Française 44 (1979), p.9-26. Reportamo-nos também aos estudos desenvolvidos por Jacqueline Authier-Revuz sobre as 'non coincidences du dire'. Em Português: 'Palavras incertas: as não coincidências do dizer' (Campinas: Ed. Da Unicamp, 1998).

12 O filósofo francês Michel Pêcheux apresenta sua concepção de subjetividade baseada na noção de heterogeneidade do sujeito. Ver 'Por Uma Análise Automática do Discurso', Campinas: Ed. Da Unicamp, 1990.

13 Trabalhamos com a versão em espanhol 'Hacia Uma Filosofia del Acto Etico (1997) traduzida por Tatiana Bubnova. A tradução para língua Portuguesa é de nossa responsabilidade. 
são ao mesmo tempo internalizadas e externalizadas, emergindo em nosso discurso para refletir a própria condição de subjetividade que nos qualifica sob diferentes circunstâncias.

Não poderíamos, de acordo com esta perspectiva, pensar sobre as relações entre subjetividade, cultura e valores sem uma leitura dialética dos limites sócio-políticos que dividem as classes e ao mesmo tempo nos remetem a diferentes visões de mundo (weltanschauungen). Tais visões de mundo estão relacionadas à divisão do trabalho, às diferentes formas de produção simbólica e também aos modos como os sujeitos são divididos pela língua que falam.

As diferentes linguagens, dialetos e jargões que os trabalhadores, camponeses, pescadores, ladrões, mendigos, estudantes e cientistas usam, por exemplo, refletem os modos como cada classe está articulada como uma comunidade ideológica, linguística e cultural e elas atestam o modo como cada um reconhece o outro por suas formas de produzir e existir.

O deslocamento, portanto, dos domínios da língua para os domínios do discurso implica a necessidade de pensar sobre os lugares atribuídos aos sujeitos e sobre os modos como estes se representam no discurso. Não podemos seguir ignorando os papéis do domínio da experiência, o papel da compreensão da experiência, bem como o lugar que a memória ocupa no discurso para explicar o trabalho concreto dos sentidos.

Em 'Questões de Literatura e de Estética' ${ }^{14}$ (1990) Mikhail Bakhtin retoma questões sobre o discurso, considerando que este pode ser somente compreendido como expressão de relações derivadas da intersecção de vozes sociais produzidas em diferentes espaços e tempos. Estas vozes conduzem as fronteiras entre os enunciados e seus conteúdos à opacidade. É necessário entender os efeitos que produzem para os ouvintes/leitores, analisando os modos através dos quais elas são reportadas para o discurso do outro e através dos quais circulam em diferentes contextos.

Por outro lado, o processo de intersecção entre o espaço e a temporalidade configura o discurso como um objeto inacessível à linearidade. Bakhtin denomina de chronotopos ${ }^{15} \mathrm{a}$ propriedade que escapa da condição de linearidade do tempo e do espaço.

Considerando a perspectiva da Física, podemos dizer que o tempo se move sempre à frente. Da perspectiva de Mikhail Bakhtin a relação entre tempo e espaço não pode ser examinada simplesmente como um eixo de sucessões. Deste modo, servindo-se de alguns parâmetros da Teoria da Relatividade, mas ao mesmo tempo interpretando as relações espaço-tempo, Bakhtin investiga como os movimentos da mente humana podem ser prospectivos e regressivos e como podem ser objetos de interpretação sob certas circunstâncias inscritas nos acontecimentos.

A noção de acontecimento do enunciado, proposta por Volochinov, funciona, portanto, para explicar como as contradições operam para caracterizar as relações entre o Estado e a sociedade e entre as superestruturas e a infraestrutura.

É possível explicar os modos através dos quais as superestruturas podem controlar as forças sociais e como as forças sociais constroem imaginários que as representam em diferentes espaços sociais e históricos , considerando as relações conflitantes que mantêm com as superestruturas.

De acordo com esta perspectiva, as relações espaço-tempo e os modos como as vozes sociais se cruzam, considerando as referências de Mikhail Bakhtin em 'Questões de

14 Estamos trabalhando com a versão brasileira de 'Questions of Literature and Aesthetics', São Paulo: Ed. Hucitec, 1990.

15 Segundo Bakhtin (1990:21) a palavra chronotopo foi originalmente usada em matemática e explicada com base na Teoria da Relatividade. 
Literatura e de Estética' (1990), estamos autorizados a compreender as relações entre enunciados e acontecimentos dentro de um contexto de luta de classes como uma questão ética. E não podemos mais fragmentar ética e estética nos domínios da Literatura.

É importante considerar também que as representações do modo como os sujeitos se reconhecem nas correlações de força entre as classes nos permitem refletir sobre as condições através das quais as superestruturas conduzem suas ações promovendo, exclusões, divisões, silêncio e opressão das forças sociais, e, por outro lado, faz-se necessário pensar sobre as condições em que as forças sociais se organizam e produzem seus próprios sentidos como corpo social.

Há relações que podem ser consideradas nas circunstâncias em que as superestruturas colocam-se acima da sociedade ${ }^{16}$, promovendo ações que intervêm nas próprias condições de vida das forças sociais e no processos de subjetivação dos sujeitos. Mas toda essa dialética pressupõe conseqüências que não são previsíveis, considerando que a compreensão das ações e dos discursos do outro implicam sempre uma reação ativa, uma réplica que trabalha de modo similar a uma contrapartida, conforme propõe Volochinov (1973).

Se o signo, entretanto, pode trabalhar somente com múltiplos sentidos em esferas simbólicas e sócio-históricas, considerando que se inscreve em diferentes enunciados concretos produzidos em eventos vivos, então, para pensar-se sobre os modos através dos quais o sujeito produz sentidos faz-se necessário compreender que o acontecimento inscrito em uma dimensão política necessita romper com as condições 'objetivas' que nos conduzem ao empirismo da unidade do sujeito. Deste modo, para compreender o trabalho do signo é preciso desconstruir a estabilidade dos sentidos que a palavra parece adquirir na língua.

$\mathrm{O}$ acontecimento do enunciado, segundo esta ótica, constrói uma deontologia que divide os sujeitos em relação aos sentidos que inscrevem em seus enunciados, bem como em relação às vozes sociais as quais se filiam e que contribuem para delimitar seus 'espaços de dizer'.

Assim, uma leitura sobre os modos como o sujeito e o sentido são constituídos na ordem simbólica e na 'arena' da divisão de classes, de acordo com nossa ótica, nos permite representar as relações dialéticas entre a superestrutura e as forças sociais. Em outras palavras, podemos representar o processo da luta de classes fragmentado em diferentes esferas de poder na sociedade.

Desta forma, compreender o 'acontecimento do enunciado' (sobytie vizkazivanie) tal como é qualificado por Voloshinov em 'Chto Takoe Yazik' [ O Que é a língua e a linguagem] (2010) implica considerar que os limites entre os enunciados são bastante tênues porque o próprio enunciado é constituído como uma composição híbrida de espaço-tempo, repleto de vozes e sentidos que representam diferentes posições ideológicas, 'marcadas' de forma especial: estas fronteiras não são transparentes em sua materialidade linguística, mas a materialidade semiótica que as constitui através do gesto, da entonação, dos sentidos que as palavras adquirem nos acontecimentos, nos conduz a diferentes valores inscritos nos enunciados.

Esta seria a condição real do discurso, pelo modo como é qualificado em 'Marxismo e Filosofia da Linguagem' (1973). E é justamente esta condição que permite justificar porque há ' um profundo abismo' entre a materialidade da língua- a sintaxe - e os componentes do discurso, já que a sintaxe pode ser explicada somente pelo sistema lingüístico

16 É preciso salientar que nos regimes democráticos as superestruturas precisam estar a serviço da sociedade e não estar distantes dela. As superestruturas não podem organizar suas metas divorciadas dos interesses das forças sociais. 
e a materialidade que constitui o enunciado, tomado no acontecimento, somente pode ser percebida quando tomada em um universo social e em um domínio ideológico.

É preciso considerar também que de acordo com 'Marxismo e Filosofia da Linguagem' não há lugar para relações objetivas e universais que delimitam os sentidos que as palavras adquirem como réplicas imediatas da realidade. Deste modo, torna-se necessário observar que as mesmas palavras podem ser tomadas, por exemplo, como réplicas de diálogos conflitantes e obter valores distintos de acordo com os acontecimentos em que se inscrevem.

A fim de ilustrar estas questões podemos nos reportar ao uso de algumas expressões em diferentes contextos de produção. A expressão 'Todo o poder de Estado aos Sovietes' empregada por bolcheviques durante o período de transição política do regime aristocrático ao regime comunista na URSS produziu efeitos positivos para a criação de um Estado revolucionário na política do novo regime. Não obstante, quando a burguesia une-se aos mencheviques a fim de explodir os movimentos revolucionários a mesma expressão 'Todo poder aos sovietes' parece ser quixotesca, tornando-se objeto do desprezo.

O slogan 'Vamos unir o capital ao trabalho' proferido pelo Presidente Luiz Inácio Lula da Silva em órgãos da mídia durante sua campanha eleitoral à Presidência do Brasil com a intenção de realizar uma aliança entre o Partido dos Trabalhadores e o Partido Liberal (PL), pode ser avaliado como hilário por militantes comunistas e socialistas brasileiros, considerando-se o fato de que onde está o capital está a mais valia e onde o trabalho é fundamental por seu valor, não pode haver mais valia. Entretanto, este slogan circulou entre os grupos políticos durante sua campanha e produziu efeitos inesperados. Um dos efeitos mais importantes foi o apagamento do fato de que forças políticas antagonistas são movidas por interesses opostos.

Podemos afirmar, então, que o trabalho dos sentidos no discurso é composto por uma pluralidade de acentos avaliativos constituídos pelos valores que as palavras adquirem em diferentes contingências. Deste modo, o fenômeno da polissemia pode ser tomado como uma das condições fundamentais do funcionamento orgânico do discurso; em outras palavras, da 'língua viva' conforme propõe Volochinov (2009).

Há somente oposição entre denotação e conotação quando opomos a linguagem da vida, utilizada nas atividades diárias, em diferentes esferas da vida social e nas quais acentos ideológicos se inscrevem à língua representada como 'ilustração da monossemia'

Somente uma concepção de língua que exclua suas condições concretas de uso poderia apresentar simetrias entre referentes e significações. A língua, neste caso, é tomada como mero objeto do conhecimento, de modo irreal, incapaz de refletir as determinações históricas que a afetam e, em conseqüência, sobre suas implicações.

Os lingüistas criaram uma ficção em que a monossemia constitui um único aspecto da realidade dentro de um sistema, enquanto para o discurso, tomado como objeto, nenhuma significação é única, "idêntica a si mesma" (ibid.,p.106), uma vez que as relações entre os significantes e significados estão inscritas em universos sócio-históricos distintos e dependem da cadeia de eventos, nos quais os sujeitos são ao mesmo tempo protagonistas e experienciadores.

Segundo Bakhtin/Volochinov (1986, p.11) todas as formas de expressão conjugam duas facetas: um conteúdo interno e sua objetivação exterior para o outro, de tal modo que, ainda que inseparáveis, o conteúdo interno e suas formas de objetivação não se definem por um centro de organização comum.

É a expressão, portanto, que organiza e determina o trabalho dos enunciados. A função da responsividade, enquanto "palavra viva," não é simplesmente produzida em nossa 
memória porque ela tem uma origem no outro, é significada segundo nossos valores e, finalmente, é dirigida ao outro.

Deste modo, o diálogo não poderia ser entendido simplesmente como uma ressonância. Em outras palavras, trata-se de pensar como a palavra do outro adquire sentido em nossas palavras. Esta função do outro, ao mesmo tempo poderia ser pensada como uma representação simbólica apropriada em horizontes sociais distintos e definida a partir de experiências vividas pelo sujeito, dentro de diferentes campos de criatividade ideológica (cultural, científico, jurídico, político, artístico, etc...). A 'palavra viva', portanto, é uma forma de combinação entre experiências, imagens, representações e signos verbais que refletem sobre quem somos.

Para Bakhtin/Volochinov, por outro lado, a palavra não é propriedade daquele que fala, nem propriedade dos destinatários da fala, seu lugar poderia ser descrito à semelhança de uma fronteira, determinada, de uma certa forma, pelo estoque social de signos que configuram os interesses dos grupos e classes sociais e, de outra, pelas situações sociais imediatas que determinam as ressonâncias.

A palavra (slovo) poderia ser comparada, desde esta perspectiva, a uma ponte: território que todos atravessam, mas que não pertence a aqueles que a atravessam, suas formas de orientação social expressam relações dialéticas entre o vivido - experienciado -e o que foi sentido. Os valores que a palavra adquire configuram ideologias que representam as formas através das quais os sujeitos são reconhecidos coletivamente e orientam suas experiências com diferentes 'acentos e valores..'

A fim de tornar explícita a condição avaliativa que as palavras adquirem nos acontecimentos, tomemos um exemplo de Bakhtin/Volochinov (1986, p.115) quando se reportam a uma situação vivida pelo 'homens famintos' expressando seus sentimentos em um contexto com outros homens famintos (desempregados, pedintes, indivíduos que vivem abaixo da margem de pobreza) que necessitam alimentar-se. Buscaremos analisar esta situação dentro do contexto 'Fome Zero', um slogan brasileiro que circulou durante o governo Luiz Inácio Lula da Silva e que remete à idéia de 'povo sem fome'. Este slogan pretendia criar um comportamento de solidariedade e encorajar o povo brasileiro a ajudar os desempregados e pedintes dando-lhes alimentos. Vamos, antes de tudo, descrever algumas condições de vida e de compreensão da realidade social da pobreza para aqueles que convivem com ela.

Um homem pode ser consciente de sua condição de pobreza: a) como algo 'casual, acidental, fortuito' sem a possibilidade de reconhecer-se entre aqueles que sofrem as mesmas privações como uma classe. A pobreza para este indivíduo será identificada como vergonha, como inferioridade, como rejeição individual, como acidente do destino, mas nunca como uma forma de exclusão produzida pela sociedade onde ele vive.

Outro homem, entretanto, pode estar consciente do lugar que ocupa dentro de uma organização social, observando o modo como a sociedade que o exclui costuma retratá-lo. Então, ele pode reconhecer-se através de ressonâncias do discurso do outro: como um incapaz de prover suas necessidades, um pária (lembremos o discurso 'fome zero') como um marginal e até mesmo como alguém que vive fora das regras da sociedade.

No primeiro caso, o discurso em torno da pobreza será constituído por um acento de resignação, de pena, de vergonha. O pedinte pode aproximar-se de seu interlocutor reportando-se à privação sofrida, às infelicidades, às tragédias de sua vida, que o conduziram à marginalidade, à mendicância e pedir ajuda.

No segundo caso, o diálogo com o interlocutor não será mais configurado como 'um drama pessoal', ele pode emergir coberto pela necessidade de negar uma imagem construída 'externamente' e que está colada a sua condição de pobreza como se fosse algo 'natural'. 
Ele pode aproximar-se de seu interlocutor, portanto, para pedir-lhe ajuda, já afirmando que não rouba, assalta ou pratica extorsão com os outros, mas pede ajuda porque precisa.

Como se pode observar, não é somente a fome, a privação em si mesma que organiza o 'centro' de enunciados destes pedintes quando interpelam seus interlocutores a fim de obter auxílio material, mas os modos através dos quais adquirem consciência através das experiências no meio social em que estão envolvidos.

O 'modelo' de discurso de cada um, suas expressões, neste caso, na contingência do limite da privação será orientado, por um lado, de acordo com o nível de alienação do indivíduo em relação aos modos como a sociedade o exclui, ou mesmo, de acordo com os modos como a sociedade discursiviza as condições de existência dos excluídos e, finalmente, de acordo com os lugares que estes indivíduos marginalizados atribuem a si próprios quando se acercam de seus interlocutores. Portanto, enquanto o primeiro homem pede desculpas por ser necessitado, o segundo age de modo coercitivo, inscrevendo as imagens e discursos de outros no seu discurso e, assim, intimidando seu interlocutor.

Mikhail Bakhtin em 'Questões de Literatura e de Estética' observa que não há meio de pensar em torno do enunciado concreto sem considerar que este emerge, de modo significativo, dentro de um determinado contexto social e histórico, agregando 'milhares de fios ideológicos existentes, conduzidos por uma consciência ideológica em torno de um objeto específico' (1990, p.86).

Deste modo, pode-se dizer que o enunciado concreto está ativamente inscrito nas formas como o diálogo representa os valores de um corpo social, desde uma perspectiva heterofônica. $\mathrm{O}$ enunciado concreto incorpora em seu interior alguns índices que operam como respostas às falas do corpo social enquanto réplicas, como uma forma de dar consistência ao seu objeto, e, ao mesmo tempo, imprimindo marcas neste corpo que mostra de que forma o sujeito toma consciência do modo como ' as palavras de outrem' ecoam em seu discurso e transformam as possibilidades de 'arranjar' seus próprios sentidos.

Os diferentes aspectos estilísticos e semânticos do discurso, sob esta perspectiva, são compilados por um processo de interação dialógica, cujas relações são produzidas através das experiências cotidianas e mediadas por signos que materializam a consciência dos sujeitos sobre sua própria realidade.

O interpretável no discurso, portanto, pode ser entendido como um trabalho de mediação entre os sentidos tomados das experiências da vida, da palavra do outro e dos valores que estas adquirem no discurso dentro de um processo dialógico. Neste processo, os sentidos tornam-se complexos por não serem nem individuais, nem universais e por adquirirem expressão própria. Deste modo é o processo de compreensão que permite aos sujeitos, a partir de uma determinada ordem social, apreender valores e sentidos produzidos nas condições em que suas experiências são mediadas pelas ordens simbólica e social.

A partir da perspectiva de Bakhtin $\backslash$ Volochinov (1986), portanto, todas as condições de representação dos objetos necessitam de um trabalho de mediação que pressupõe um movimento de não-coincidência das relações imediatas entre a realidade e a ordem simbólica.

O domínio das 'palavras interiores' como parte do trabalho dos sentidos não existe se não pudermos conhecer as condições exotópicas que compõem as palavras como forma de objetivar as sinapses entre as experiências da vida e os valores simbólicos que os significantes adquirem.

A fim de complementar as idéias sobre o discurso como um trabalho simbólico, algumas questões propostas por Mikhail Bakhtin em 'O Discurso na Poesia e o Discurso no Romance' (1990) permitem com que estabeleçamos correlações entre os domínios do discurso e do diálogo. O discurso emerge do diálogo como uma réplica 'viva', constituída de um conjunto de orientações que encontram sua origem e seu eco no dizer de outrem, 
ao mesmo tempo em que responde a outrem. Deste modo, de acordo com Bakhtin (1990) mesmo sendo constituído em uma atmosfera de 'coisas já ditas', ele se orienta como uma resposta que ainda não tinha sido enunciada- embora fosse invocada e esperada.

É através da função responsiva, pois, que se pode compreender a força essencial do discurso. É esta força que permite ao falante, na qualidade de interlocutor, estar livre de uma função passiva e colocar as 'palavras interiores' em contraponto com o diálogo 'externo', produzindo importantes conseqüências, tais como abstrair os enunciados da esfera da reprodução.

Este viria a ser também um dos argumentos essenciais para colocar a função responsiva em um lugar de destaque, conforme Bakthin\Volochinov (1986:47) em 'Marxismo e Filosofia da Linguagem': “a verdade viva' está sempre acompanhada pela contradição entre o que é reproduzivel e o que é transformável, entre a estabilidade do ontem e a instabilidade do amanhã.".

Neste processo, pois, é possível configurar as condições de funcionamento do discurso como um exercício de expressão regulado por uma lógica orgânica que pode ser traduzida pelo princípio de não-reprodução do que é dito e considerar a responsividade como uma força, o trabalho ativo em que os sentidos tornam-se outros.

Considerando tais questões, o discurso é o domínio onde a significação torna-se orgânica porque ela está implicada nas respostas que são invocadas pelo exercício do deslocamento, da transformação da "palavra já sedimentada em uma palavra mutável, sujeita às contingências externas que são convocadas, de modo permanente, para um trabalho de metaforização ${ }^{17}$, ou seja, para transferir as propriedades de um determinado significante para outros, pressupondo deslocamentos dos sentidos.

O item lexical democrata, por exemplo, segundo o Dicionário brasileiro de sinônimos e antônimos Houaiss $(2011)^{18}$, que inscreve em seu corpus os efeitos das contradições do corpo social, é sinônimo de igualitário, anti-autoritário, mas também de liberal e elitista. Como explicar tais contradições? Parece que os próprios acontecimentos no campo político podem melhor explicar.

Se nos reportarmos ao Partido Liberal brasileiro que compôs uma aliança com o governo Lula desde sua primeira eleição, veremos que este Partido, em suas condições de formação, recebe esta designação ao ser constituído notadamente por profissionais liberais adeptos da 'livre iniciativa', com métodos de produção capitalista. O Partido Liberal, contudo, ao sofrer um "stress político" diante da aliança com um Partido que foi legitimado como defensor de métodos de produção não capitalista adota uma nova designação 'Democratas' a fim de colar uma nova imagem à instituição.

As propriedades do significante liberal, portanto, que podem ser identificadas a práticas capitalistas são apagadas somente de modo aparente, porque de fato elas são transferidas para a nova designação.

Ao produzir uma nova relação de equivalência entre os atributos de ser capitalista e os atributos de ser democrata, os membros do primeiro (Partido Liberal) respondem às críticas dos socialistas brasileiros com um eufemismo, como forma de responsividade; ela tem a função de apagar a carga semântica negativa adquirida pelo item lexical liberal, transferindo seus atributos para um novo item lexical que se torna ambíguo no acontecimento.

Para compreender melhor a ambigüidade destas transferências é importante lembrar

17 Adotamos a noção de metáfora proposta por Frank Palmer em 'Semantics: a new outline' (1976) que descreve o trabalho metafórico das expressões pela transferência de propriedades de alguns significantes para atributos de diferentes palavras conferindo-lhes nova vida.

18 Reportamo-nos ao Dicionário Houaiss: sinônimos e antônimos’, São Paulo: Publifolha, 2011. 
que, segundo Bakhtin\Volochinov (1986, p.98) a Linguística "elaborou seus métodos e categorias trabalhando com monólogos mortos" e diálogos abstratos, sem observar sua própria realidade entre as forças sociais. Ela deveria observar as transformações contínuas das línguas, suas contradições, dando atenção às diferentes formas de discurso produzidas no cotidiano, nas praças, feiras, passeatas, movimentos populares finalmente, em situações concretas nas quais as classes se reconhecem e se confrontam. Estas seriam algumas lacunas que converteram a Ciência da Linguagem em alienante, se considerarmos o funcionamento orgânico da linguagem na vida social.

\section{Conclusão}

Este estudo buscou levantar algumas questões com o objetivo de caracterizar as condições concretas de uso da língua e de funcionamento do discurso como um objeto híbrido sob a perspectiva dos Estudos de Semiótica desenvolvidos no contexto soviético.

Sob a ótica de questões exotópicas e, ao mesmo tempo, a partir da análise do trabalho das estruturas lingüísticas no discurso e dos modos como os enunciados adquirem sentidos, buscamos investigar a complexidade das relações que nos permitem caracterizar nosso objeto como uma unidade complexa e heterogênea. Investigamos, portanto, a influência dos elementos sociais e estruturais para a compreensão das condições que transformam a língua, descrita pelos lingüistas como um sistema abstrato, em 'matéria viva'.

Orientando-nos por diferentes questões apresentadas por Mikhail Bakhtin e Valentin Volochinov concluímos que os domínios do discurso, caracterizados por suas condições materiais necessitam considerar as tendências ideológicas: os valores que as palavras adquirem em diferentes situações históricas. E, por outro lado, devem estar orientados em relação ao funcionamento da responsividade, que é a força que permite explicar porque 'as palavras conhecidas' podem tornar-se sempre desconhecidas em situações concretas, na medida em que adquirem novos sentidos nas contingências em que os enunciados são produzidos.

\section{Referências}

AUTHIER-REVUZ, Jacqueline. Palavras incertas: as não-coincidências do dizer. Campinas: Ed. da Unicamp, 1998.

BAKHTIN, Mikhail. Para uma filosofia do ato responsável. São Carlos: Ed. Pedro \& João, 2012.

. Questões de literatura e de estética: a teoria do romance. São Paulo: Unesp/ Hucitec, 1990. Trad. Aurora Fornoni Bernardini et al.. BAKHTIN, Mikhail (VOLOCHINOV, V.) Marxismo e filosofia da linguagem. Problemas fundamentais do método sociológico na Ciência da Linguagem. São Paulo: Ed. Hucitec, 1986.

BAKHTINE, Mikhail.( VOLOCHINOV,V). Le marxisme et la philosophie du langage. Essai d'application de la methode sociologique en linguistique. Paris: Minuit Ed., 1977. BAKHTINE, Mikhail. Esthétique de la creation verbale. Paris: Ed. Gallimard, 1984. . Questions of Literature and aesthetics.

BAJTIN, M.. La palabra em la vida y la palabra en la poesia. Hácia uma poética sociológica. In: Hacia una filosofia del acto ético. De los borradores y otros escritos. Puerto Rico: Anthropos Ed., 1997. 
BAJTIN, Mijail. Hacia uma filosofia del acto ético. De los borradores y otros escritos. Puerto Rico: Ed. Anthropos, 1997.

DUCROT, Oswald. O dizer e o dito. Campinas: Ed. Pontes, 1987.

HALLIDAY, M.A., HASAN, R. Cohesion in English. London: Longman Editions, 1976.

HOUAISS, A. Dicionário Houaiss: sinônimos e antônimos. São Paulo: Publifolha, 2011.

JAKUBINSKII, L. O dialogicheskoi rechi. Moscou: Nauka Ed., 1986.

. Une Linguistique de la parole. Limoges: Ed. Lambert-Lucas, 2012.

PALMER, Frank. Semantics: a new outline. Cambridge: Cambridge University Press, 1976

PÊCHEUX, Michel. Análise automatica do discurso. In; Por uma análise automática do discurso. Uma introdução à obra de Michel Pêcheux. Campinas: Ed. da Unicamp, 1990. VOLOŠINOV, Valentin. Marxism and the philosophy of language. Cambridgel Massachusetts: Harvard University Press, 1973.

LAHTEENMÄKI, Mika. Estratificação social da linguagem no discurso sobre o romance; o contexto soviético oculto. In: Mikhail Bakhtin: contribuições para a filosofia da linguagem e estudos discursivos. ZANDWAIS, Ana (org.), Porto Alegre: SagraLuzzatto Ed., 2005.

VOLOCHINOV, V. El marxismo y la filosofia del lenguage: los principales problemas del método sociológico em la ciência del lenguaje. Madrid: Alianza Editorial, 1992. Traducción Tatiana Bubnova VOLOCHINOV, Valentin. A construção da enunciação e outros ensaios. São Carlos: Ed. Pedro \& João, 2013. Organização, trad. E notas: João Wanderley Geraldi, VOLOŠINOV, Valentin. Marxisme et philosophie du langage. Les problems fondamentaux de la méthode sociologique dans la science du langage. Limoges: Ed. Lambert-Lucas, 2010. Traduite par Patrick Sériot et Inna Tylkowski-Ageeva.

. Qu'est ce que la langue et le langage? Limoges: Ed. Lambert-Lucas, 2010, p.521-572.Traduit par Patrick Sériot et Inna Tylkowsky Ageeva. 